\title{
IGF2R Expression is Associated with the Chemotherapy Response and Prognosis of Patients with Advanced NSCLC
}

\author{
Zhennan Tian Guodong Yao Hongtao Song Yang Zhou Jingshu Geng \\ Department of Pathology, The Third Affiliated Hospital of Harbin Medical University, Nangang District, \\ Harbin China
}

\author{
Key Words \\ IGF-2 receptor • Non-small cell lung cancer • Chemotherapy • Prognosis
}

\begin{abstract}
Background: Insulin-like growth factor (IGF) pathway has been suggested as a new molecular target for the treatment of cancer including Non-small cell lung cancer (NSCLC). We postulated that IGF-2 receptor (IGF2R) may be associated with treatment response and prognosis of NSCLC patients receiving chemotherapy. Methods: A total of 464 patients with inoperable advanced stage of NSCLC were enrolled. All patients received platinum-based chemotherapy. Meanwhile, the IGF2R expression in tumor samples was detected by Immunohistochemical analysis. The IGF2R expression was inhibited in several human NSCLC cell lines (H292, A549, $\mathrm{NCI}-\mathrm{H} 460$, Calu-3 and NCI-H23) after small interfering RNA (siRNA) transfection and the cellular biology behavior were evaluated. Results: Of all NSCLC patients, 204 had high IGF2R expression and 260 had low IGF2R expression. The low IGF2R expression was significantly associated with the smoking status, higher tumor stage, and poorer differentiation status of these patients. Notably, we found that the low IGF2R expression was closely associated with the chemotherapy response in NSCLC patients. Patients with low IGF2R expressions had a poorer prognosis than those with high IGF2R expressions. IGF2R inhibition by si-RNA technique in NSCLC cell lines increased the proliferation, migration and invasion abilities, but reduced the apoptosis rate. IGF2R silencing significantly enhanced the chemo-resistance of NSCLC cell lines to cisplatin treatment. Conclusion: The IGF2R expression in tumor is associated with the chemotherapy response and prognosis of Patients with advanced NSCLC.
\end{abstract}

Copyright $\odot 2014$ S. Karger AG, Basel

T. Zhennan and Y. Guodong contributed equally to this work and are joint first authors. 


\section{Introduction}

Non-small cell lung cancer (NSCLC) accounts for 80-85\% of all lung cancer cases and its 5-year survival rate is very poor (about 15\%) [1]. Many NSCLC patients are diagnosed at late stage, missing the chance for surgical resection. Platinum-based chemotherapy is the standard first-line chemotherapy for inoperable NSCLC; however, drug resistance negatively influences the clinical outcome of patients receiving chemotherapy [2-4]. The identification of new makers predicting the chemotherapy response has become the focus of intense research $[5,6]$.

Recently, the insulin-like growth factor (IGF) pathway has been suggested as a new molecular target for the treatment of cancers including NSCLC [7-10]. IGF1 and IGF2 are two major members of IGF family. To date, the association between IGF1 and it receptor (IGF1R) with tumorgenesis has been well documented, however, the role of IGF2 and its receptor (IGF2R) in tumor development remains large unknown. Structurally, the binding of IGF2 with IGF2R lacks an intracellular tyrosine kinase domain, which acts mainly as a "buffer' for IGF2 bioactivity [11]. In human cells, loss of IGF2R function has been associated with the development of cancers of the breast, lung, liver and ovary $[12,13]$. However, IGF2R expression was not associated with the clinical features of squamous-cell laryngeal cancer [14].

A recent study suggests that Insulin-like growth factor-1 receptor (IGF-1R) may be used as a predictor for the treatment resistance to the tyrosine kinase inhibitor gefitinib in NSCLC patients [15]. However, the association between IGF2R with the chemotherapy response and prognosis of NSCLC has not been documented. We prostituted that the tumor IGF2R expression may affect the treatment response in NSCLC patients receiving Platinumbased chemotherapy. In this study, we enrolled patients with advanced NSCLC to test this hypothesis.

\section{Materials and Methods}

\section{Patient enrollment}

A total of 464 patients with advanced stage of NSCLC, namely, stage III (A+B) and IV NSCLC were enrolled into this study. The staging system we used was the 7th edition of the TNM system [20]. All patients had received platinum-based chemotherapy after diagnosis and did not receive surgical treatment (Table 1). The study was approved by the ethics committees of our hospital and written informed consent was obtained from each participant. Patient responses to treatment were determined by the WHO criteria, which classify the response into four categories: complete response (CR), partial response (PR), stable disease (SD), and progressive disease (PD) [16]. CR was defined as complete disappearance of all measurable lesions. PR required at least $50 \%$ reduction in measurable lesions. Patients with SD had less than a $50 \%$ decrease or no more than a $25 \%$ increase in the size of measurable lesions. PD was assigned to patients when measurable lesions increased by more than $25 \%$ or new lesions appeared. For prognosis analyses, the overall survival (OS) and progression free survival (PFS) were the end points in this study. OS was calculated from the date of chemotherapy to the date of last follow-up or death from any cause. PFS was defined as the interval between the date of chemotherapy and the date of confirmed progression.

\section{Immunohistochemical analysis and evaluation}

Tumor samples were obtained from the biopsy before the start of chemotherapy. The tissues were fixed, paraffin embedded, and cut to $5-\mu \mathrm{m}$-thick sections for immunohistochemistry. Briefly, the slides were incubated with IGF2R primary antibodies (1:200, SIGMA, USA). The immunoreactive products were visualized by the catalysis of 3,3'-diaminobenzidine (DAB). The expression of IGF2R was evaluated by a semiquantitative approach based on staining intensity (SI) and percentage of positive cells (PP), to create the immunoreactive score (IRS) as follows: IRS=SIxPP, for each sample, as previously described. Intensity was scored as follows: $0=$ no staining, $1=$ weakly positive, $2=$ moderately positive, and $3=$ strongly positive. The scoring of the staining pattern was based on the percentage of positive tumor cells: $0=0-5 \%, 1=6-$ 
$25 \%, 2=26-50 \%, 3=51-100 \%$ ). The localization of staining for each protein was also indicated either as cytoplasmic or cytoplasmic/membranous or membranous [14].

Tumor Cell line Culture and small interfering RNA (siRNA) transfection

Several human NSCLC cell lines, namely, H292, A549, NCI-H460, Calu-3, NCI-H23, were cultured to 75\% confluence before small interfering RNA (siRNA) transfection. The down-regulation of IGF-2 receptor was performed by targeting three different sites downstream of the start codon using sequence-specific siRNAs: 1 : 5'-GGAGGUGCCAUGCUAUGUGtt-3', 5'-CACAUAGCAUGGCACCUCCtt-3'; 5'-GGGUUUUCUUUUGACUUAUtt-3', $5^{\prime}$-AUAAGUCAAAAGAAAACCCtg- $3^{\prime}$ and $5^{\prime}$ CGCAGGTAACGATGGGAAATT $-3^{\prime}, 5^{\prime}$ - TTTCCCATCGTTACCTGCGG $-3^{\prime}[17,18]$. Only the one targeting a site located 2050 nucleotides $\left(5^{\prime}\right.$-GGGUUUUCUUUUGACUUAUtt- $3^{\prime}$ and $5^{\prime}$-UAAGUCAAAAGAAAACCCtg-3') showed satisfactory inhibitory effect on five NSCLC cell lines. After transfection, the expression of IGF2R expression in treated cells was detected by western blot assay. After immunoblot analysis, membranes were immunoblotted with anti-IGF2R antibody (1:1000, Biocompare, USA). Membranes were then washed and incubated with a secondary antibody coupled to horseradish peroxidase.

\section{Cell Proliferation Assay}

We performed the 3-(4, 5-dimethylthiazol-2-yl)-2, 5-diphenyltetrazolium bromide (MTT, Sigma Aldrich,USA) assay to determine the cell proliferation. Briefly, cells were washed. MTT reagent was added and incubated at $37^{\circ} \mathrm{C}$ for $3 \mathrm{hrs}$. After MTT reagent removal, MTT solvent ( $10 \%$ Triton $100 \mathrm{X}$ and $0.1 \mathrm{~N} \mathrm{HCL}$ in anhydrous isopropanol) was added. Absorbance was determined in a Microwell plate reader (Model 680, Biorad, Marnes-La-Coquette, France).

\section{Cell invasion and migration assay}

The cell invasion and migration ability was evaluated using transwell inserts with $8 \mu \mathrm{m}$ pores (BD Biosciences, San Jose, CA, USA). For invasion assay, $2 \times 10^{5}$ cells in serum free medium were added to each upper compartment of the chamber pre-coated with matrigel matrix (BD Biosciences, San Jose, CA, USA). After incubation for 48 hours, noninvasive cells were removed from the upper surface of the transwell membrane, and migrated cells were fixed with methanol, stained with Giemsa and photographed under the microscope. For migration assay, $2 \times 10^{5}$ cells were placed into the top chamber without matrigel matrix pre-coated. Finally, the cells in lower compartment of the chamber that had invaded to the basal side of the membrane were counted using a light microscope in 5 random visual fields $(\times 200)$ [23].

\section{Cisplatin cytotoxicity assay}

Cell lines were seeded at $1 \times 10^{4}$ cells per well in 96 -well plates, and were transfected by IGF2R siRNA and control siRNA for $48 \mathrm{~h}$, and subsequently exposed to cisplatin at final concentrations of $0.5,1.0,2.0,4.0$ or $8.0 \mathrm{ug} / \mathrm{ml}$ for $24 \mathrm{~h}$ in triplicate wells. Cell survival was determined using a previously described colorimetric MTT assay. Mean cell viability was calculated by the ratio of absorbance units of transfected cell samples to the mean absorbance units of the control cell samples. All the experiments were repeated at least three times. The half maximal (50\%) inhibitory concentration (IC50) value is defined as concentration of cisplatin that is required for a $50 \%$ reduction in absorbance calculated from the growth curves.

\section{Terminal Deoxynucleotidyl Transferase dUTP Nick End Labeling (TUNEL) Assay}

The apoptosis in the cultured cell lines were detected by in situ DeadEndTM Colorimetric Apoptosis Detection System (Promega, Madison, USA) according to the manufacturer's instructions. Briefly, cells were incubated with terminal deoxynucleotidyl transferase enzyme in a humidified chamber at $37^{\circ} \mathrm{C}$ for $60 \mathrm{~min}$. The reaction was terminated by transferring the slides to $2 \times$ sodium citrate saline solution. The sections were counter stained with DAPI. For quantitative analyses, 5 fields per section were selected. Apoptosis was indexed by counting TUNEL positive cells per 100 nuclei per section.

\section{Statistical Analyses}

Association between IGF2R expression status and clinical parameters were studied using chi-square test, or independent $t$ tests. Multivariate analysis was performed using the Cox proportional hazards model selected in forward stepwise. The odds ratios (OR) and 95\% confidence intervals (CIs) were calculated. 
Table 1. NSCLC Patient Characteristics

\begin{tabular}{cccc}
\hline Characteristics Patient & Good Responder & Poor Responder & P \\
\hline Age (years) & $55.6 \pm 6.1$ & $56.8 \pm 7.0$ & NS \\
Gender & & & \\
Male & 61 & 167 & NS \\
Female & 59 & 177 & \\
Smoking Status & & & $<0.001$ \\
Non-smokers & 58 & 33 & \\
Smoker & 62 & 311 & NS \\
Histology & & & \\
Squamous cell carcinoma & 66 & 176 & $<0.001$ \\
Adenocarcinoma & 54 & 168 & \\
Stage & & & \\
IIIA & 46 & 67 & \\
IIIB & 51 & 168 & \\
IV & 23 & & \\
Differentiation & & 68 & \\
Well & 47 & 189 & \\
Moderate & 60 & 89 & \\
Poor & 13 & 99 & \\
Chemotherapy regimens & & 156 & \\
DDP/CBP+TAX/TXT/DOC & 38 & & \\
DDP/CBP+GEM & 54 & & \\
DDP/CBP+NVB & 28 & & \\
\hline
\end{tabular}

Survival was analyzed using the Kaplan-Meier method. The log-rank test was used to analyze survival differences. The data in proliferation rate, migration, invasiveness, cisplatin cytotoxicity assays between IGF2R si-RNA and control si-RNA treated cells were compared by using ANOVA or t tests. $\mathrm{P}<0.05$ was considered statistically significant. All analyses were performed by using SAS software (version 9.2, USA).

\section{Results}

\section{NSCLC Patient Characteristics}

Of all enrolled patients, 120 patients were assigned as good responder (CR + PR) and 344 were poor responders to chemotherapy (SD + PD). No significant difference was noted in mean age, gender distribution, histology type and chemotherapy agents between good and poor responders (Table 1). However, the poor responders had higher percentages of smokers, higher tumor stage, poorer differentiation than good responders (all $\mathrm{P}<0.001$ ).

The association between IGFR2 expression and clinical characteristics of NSCLC

Representative Fig. of IGF2R staining are shown in Fig. 1a. The IGF2R immunostaining was predominantly in cytoplasm. The IGF2R expression level was assigned to high expression if the IRS score $\geq 2$, otherwise assigned to low expression [14]. The IRS value distributions for IGF2R expressions between two groups are shown in Fig. 1b. Of all NSCLC patients, 198 had high IGF2R expressions and 266 had low IGF2R expressions. Table 2 shows the association between IGF2R expression status and clinical characteristics of NSCLC patients. The low IGF2R expression were significantly associated with the smoking status (Adjusted $\mathrm{OR}=5.606, \mathrm{P}<0.001$ ), higher tumor stage (Adjusted $\mathrm{OR}=2.274, \mathrm{P}=0.0013$ ), and poorer differentiation status (Adjusted $\mathrm{OR}=2.459, \mathrm{P}<0.001$ ), (Table 2). Notably, we found that the high IGF2R expression was also significantly associated with chemotherapy response (Adjusted OR=10.638, P<0.001). We did not observe correlation between IGF2R and age, histology and chemotherapy regimens of enrolled patients (data not shown).

The IGF2R expression predicts the prognosis of NSCLC

The associations between the clinical variables and PFS as well as OS were studied by log-rank test. Patients with low IGF2R expressions had markedly shorter PFS and OS than those with high IGF2R expressions $(6.8 \pm 2.1$ vs. $8.8 \pm 2.4$, months, $\mathrm{P}<0.001$ and $11.1 \pm 7.2$ vs. 


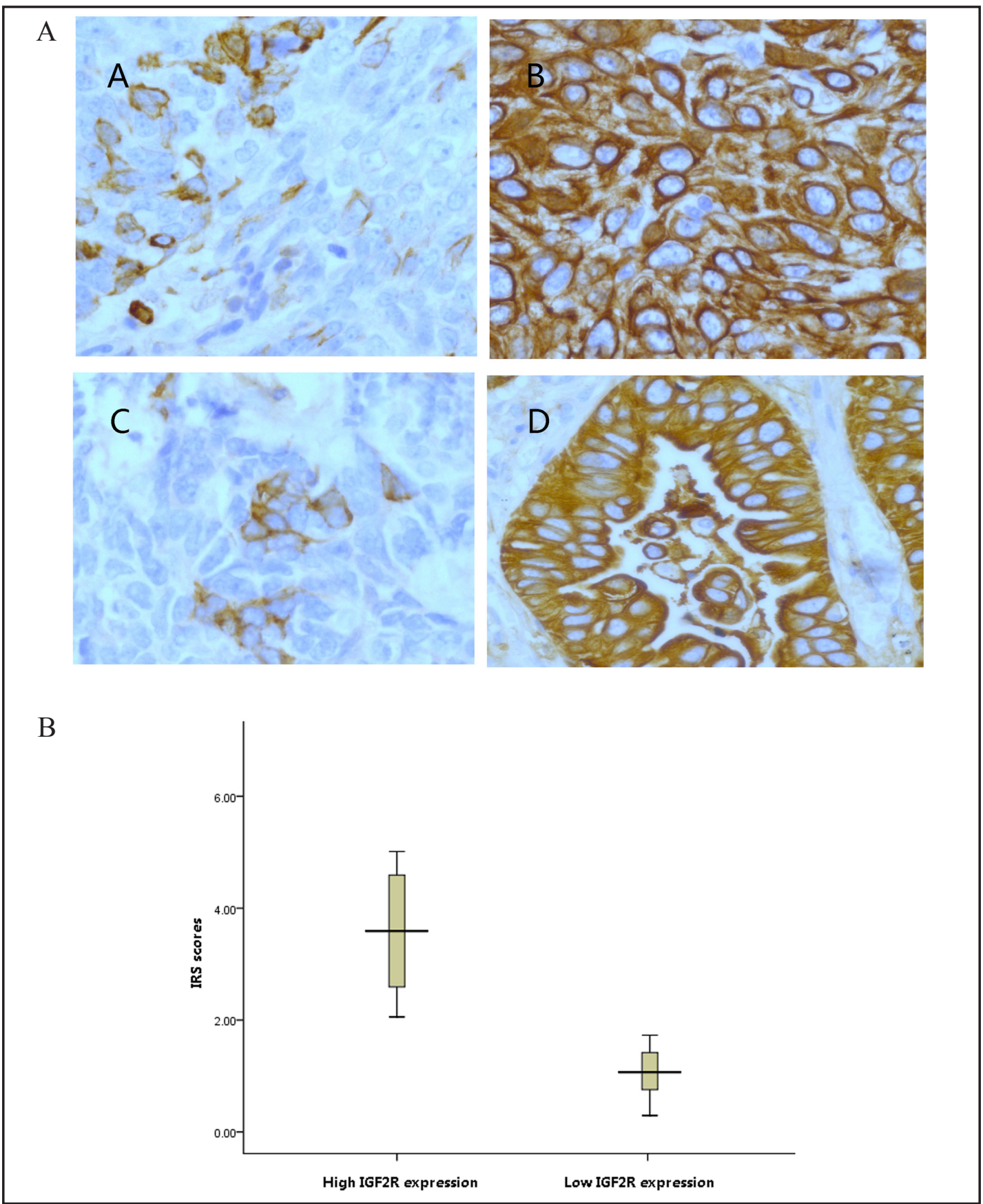

Fig. 1. (A) A shows the typical images of IGF2R expression in NSCLC samples from different patients (1 sample from 1 patient). a: low IGF2R expression in Squamous cell carcinoma sample. b: High IGF2R expression in Squamous cell carcinoma sample. c: low IGF2R expression in Adenocarcinoma sample. d: High IGF2R expression in Adenocarcinoma sample. (B) B shows the IRS scores distributions of all samples. The expression level of IGF2R was assigned to high expression if the IRS score $\geq 2$, otherwise assigned to low expression group. Of all NSCLC patients, 198 had high IGF2R expression and 266 had low IGF2R expression.

17.1 \pm 2.8 , months, $\mathrm{P}<0.001)$. Kaplan-Meier survival curves for PFS and OS are shown in Fig. $2 \mathrm{a}$ and $2 \mathrm{~b}$, respectively.

Univariate and multivariate analyses were performed by using Cox proportional hazard model to evaluate the impact of IGF2R expression and other pathological factors on the prognosis of NSCLC (Table 3). Univariate analysis showed four statistically significant 
Tian et al.: IGF2R Expresison in Advanced NSCLC

Table 2. The association between IGF2R expression status and clinical characteristics of NSCLC patients

\begin{tabular}{ccccccc}
\hline Clinical features & $\begin{array}{c}\text { Low IGF2R } \\
\text { expression }\end{array}$ & $\begin{array}{c}\text { High IGF2R } \\
\text { expression }\end{array}$ & Adjusted OR & 95\%CI & Adjusted P \\
\hline Tumor Stage & & & & & & \\
IIIA & 45 & 54 & 1 & & & \\
IIIB & 115 & 99 & 1.293 & 0.812 & 2.234 & 0.284 \\
IV & 100 & 51 & 2.243 & 1.354 & 3.453 & 0.012 \\
Smoking status & & & & & & \\
$\quad \begin{array}{c}\text { Non-smokers } \\
\text { Smoker }\end{array}$ & 102 & 157 & 1 & & & \\
$\begin{array}{c}\text { Tumor differentiation } \\
\text { Well }\end{array}$ & 158 & 47 & 5.643 & 3.437 & 8.554 & $<0.001$ \\
$\quad$ Moderate & 141 & 47 & 1 & & & \\
$\quad$ Poor & 77 & 33 & 1.122 & 0.567 & 1.7853 & 0.692 \\
chemotherapy response & & & & 1.342 & 4.365 & $<0.001$ \\
Good Responder & 21 & 99 & 1 & & & \\
Poor Responder & 245 & 99 & 10.643 & 6.467 & 14.754 & $<0.001$ \\
\hline & & & & & & \\
\hline
\end{tabular}

Table 3. Multivariate Cox proportional regression analysis on PFS and OS of NSCLC patients

\begin{tabular}{lcccccc}
\hline \multicolumn{1}{c}{ Variable } & HR & PFS & & & OS & \\
& & & & CI & $95 \% \mathrm{CI}$ & $\mathrm{P}$ \\
\hline $\begin{array}{l}\text { IGF2R expression status } \\
\text { High expression }\end{array}$ & 1 & & & 1 & & \\
$\begin{array}{l}\text { Low expression } \\
\text { Tumor stage }\end{array}$ & 2.407 & $2.216-4.854$ & $<0.001$ & 2.454 & $2.524-3.742$ & 0.003 \\
IIIA & 1 & & & & & \\
IIIB+IV & 2.415 & $2.814-4.956$ & 0.008 & 1.326 & $1.879-3.886$ & 0.009 \\
tumor differentiation & & & & & & \\
$\begin{array}{l}\text { Well } \\
\text { Moderate +poor }\end{array}$ & 1 & & & 1 & & \\
\hline
\end{tabular}

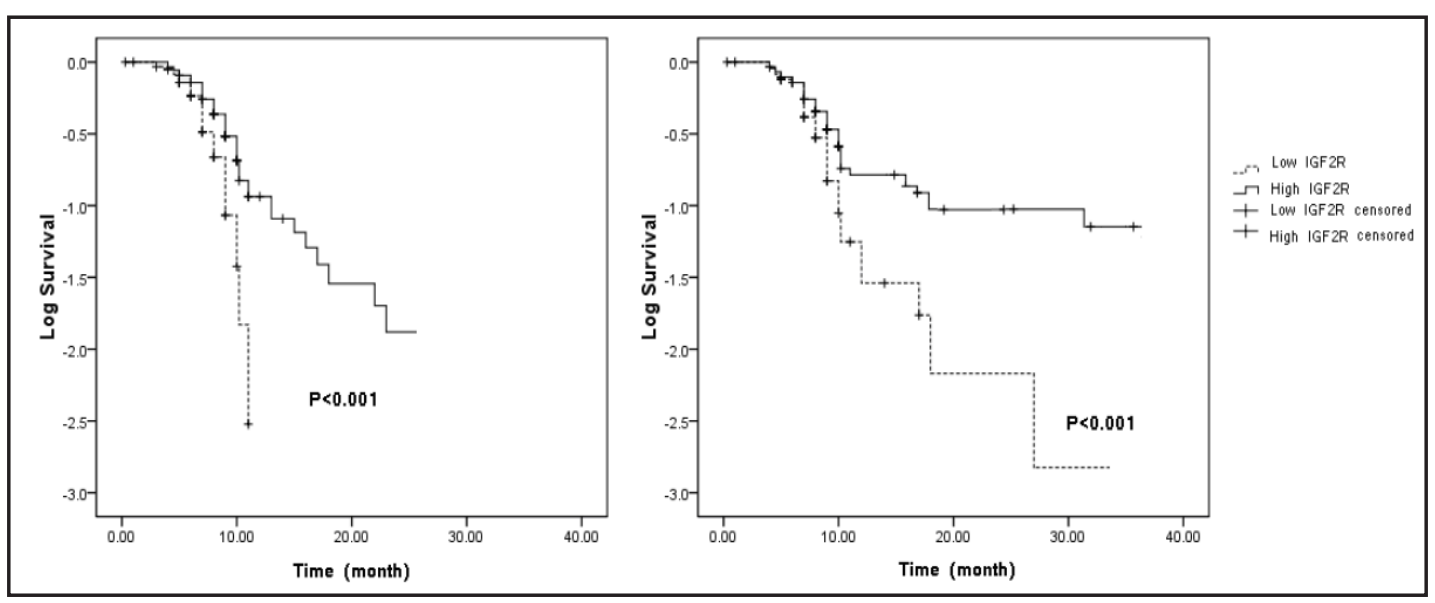

Fig. 2. Kaplan-Meier survival curves for PFS and OS. Fig. 2 show the survival curves for PFS and OS by Kaplan-Meier analyses. Patients with low IGF2R expressions had worse prognosis indicated by shorter PFS (Fig. 2a) and OS (Fig. 2b) than those with high IGF2R expressions (6.8 \pm 2.1 vs. $8.8 \pm 2.4$, months, $\mathrm{P}<0.001$ by log-rank test and $11.1 \pm 7.2$ vs. $17.1 \pm 2.8$, months, $\mathrm{P}<0.001$ by log-rank test).

variables associated with the prognosis of NSCLC: tumor stage $(\mathrm{P}<0.001)$, smoker $(\mathrm{P}=0.024)$, tumor differentiation $(\mathrm{P}=0.003)$ and IGF2R expression $(\mathrm{P}<0.001)$. The multivariate analyses confirmed that tumor stage, tumor differentiation and IGF2R expression can predict a poor prognosis in NSCLC patients (Table 3). Patients with low IGF2R expression had poorer prognosis (PFS, adjusted $\mathrm{HR}=3.32$, adjusted $\mathrm{P}<0.001$; OS adjusted $\mathrm{HR}=2.48$, adjusted $\mathrm{P}<0.001$ ). 


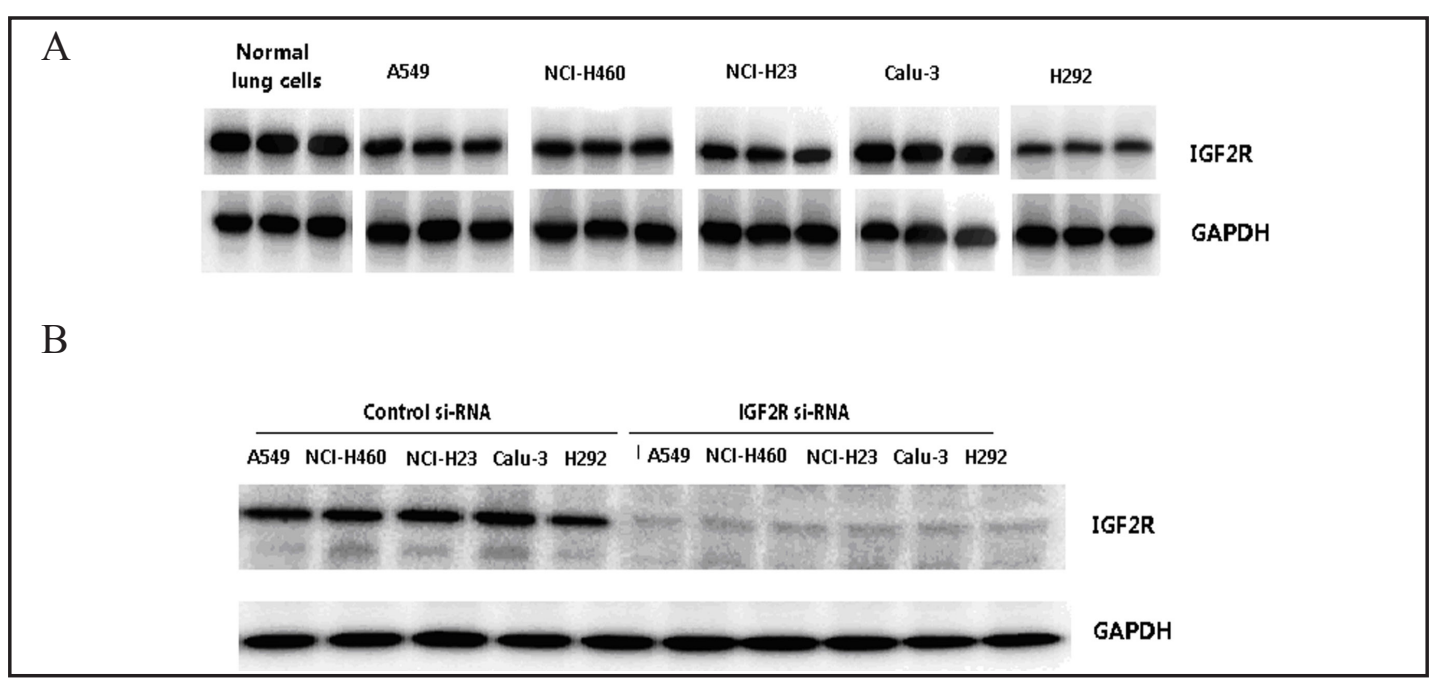

Fig. 3. Western blot results of IGF2R protein expressions in NSCLLC cell lines at baseline and after si-RNA transfection. The IGF2R protein expression by western blot assay in normal lung cell line HELF and 5 NSCLC cell lines are shown in Fig. 3a.We found the all NSCLC cells had lower IGF2R expression compared to normal lung cells(all $\mathrm{P}<0.0$, vs. normal lung cells). Among NSCLC cell lines, the Calu-3 had higher IGF2R expression, and H292 had the lowest IGF2R expression, while the other three cell lines show the similar IGF2R levels. The effect of IGF2R si-RNA transfection on target protein expression was shown in Fig. 3b. Western blot assays showed that all NSCLC cell lines treated with control si-RNA expressed IGF2R. In contrast, cells treated with IGF2R si-RNA showed dramatically decreased IGF2R protein expressions.

IGF2R inhibition on the proliferation, migration and invasion abilities of NSCLC cell lines

The IGF2R protein expression in normal lung cell line HELF and 5 NSCLC cell lines are shown in Fig. 3a. We found the all NSCLC cells had lower IGF2R expression compared to normal lung cells. Among NSCLC cell lines, the Calu-3 had higher IGF2R expression, and H292 had the lowest IGF2R expression, while the other three cell lines show the similar IGF2R levels $(\mathrm{P}<0.05)$. Western blot results shows that the IGF2R protein expressions in NSCLC cell lines were significantly inhibited by IGF2R si-RNA silencing technique (Fig. 3b). The cell proliferation assays revealed the cell growth rates were significantly increased in NSCLC cell lines after IGF2R si-RNA transfection compared to cells treated with control si-RNA (Fig. 4a). Cell migration assay showed that IGF2R knockdown significantly increased the migrated cell numbers (Fig. 4b). Furthermore, silencing of IGF2R gene dramatically enhanced the invasive ability of studied NSCLC cell lines (Fig. 4c). In contrast, cell lines receiving IGF2R si-RNA treatment had significantly decreased apoptosis rates than that receiving control si-RNA transfection (Fig. 4d).

The IGF2R si-RNA transfection induces chemosensitivity to cisplatin in cultured cancer cells

Exposure of IGF2R si-RNA-transfected cell lines to different concentrations of cisplatin induced significant proliferative inhibition (Fig. 5). The IC50 concentration of cisplatin for IGF2R si-RNA transfected cells increased significantly than control cells (A549: 3.32 vs. 1.59ug/ml; NCI-H460: 3.402 vs. $1.52 \mathrm{ug} / \mathrm{ml}$; NCI-H23: 3.56 vs. $1.62 \mathrm{ug} / \mathrm{ml}$; Calu-3: 2.06 vs. $1.03 \mathrm{ug} / \mathrm{ml}$; H292: 4.71 vs. $2.26 \mathrm{ug} / \mathrm{ml}$; all $\mathrm{P}<0.01$ ), indicating that IGF2R silencing significantly enhanced the chemo-resistance of NSCLC cell lines to cisplatin treatment. When the IC50 were compared among different cell lines, we found that the cell line with lower IGF2R expression tend to have higher IC50, while cell line with higher IGF2R expression, showed considerable reduction of IC50 $(\mathrm{P}<0.05)$. Pearson analyses revealed a negative correlation between the IC50 and the IGF2R expression ( $\mathrm{r}=-0.87, \mathrm{P}=0.002)$. 


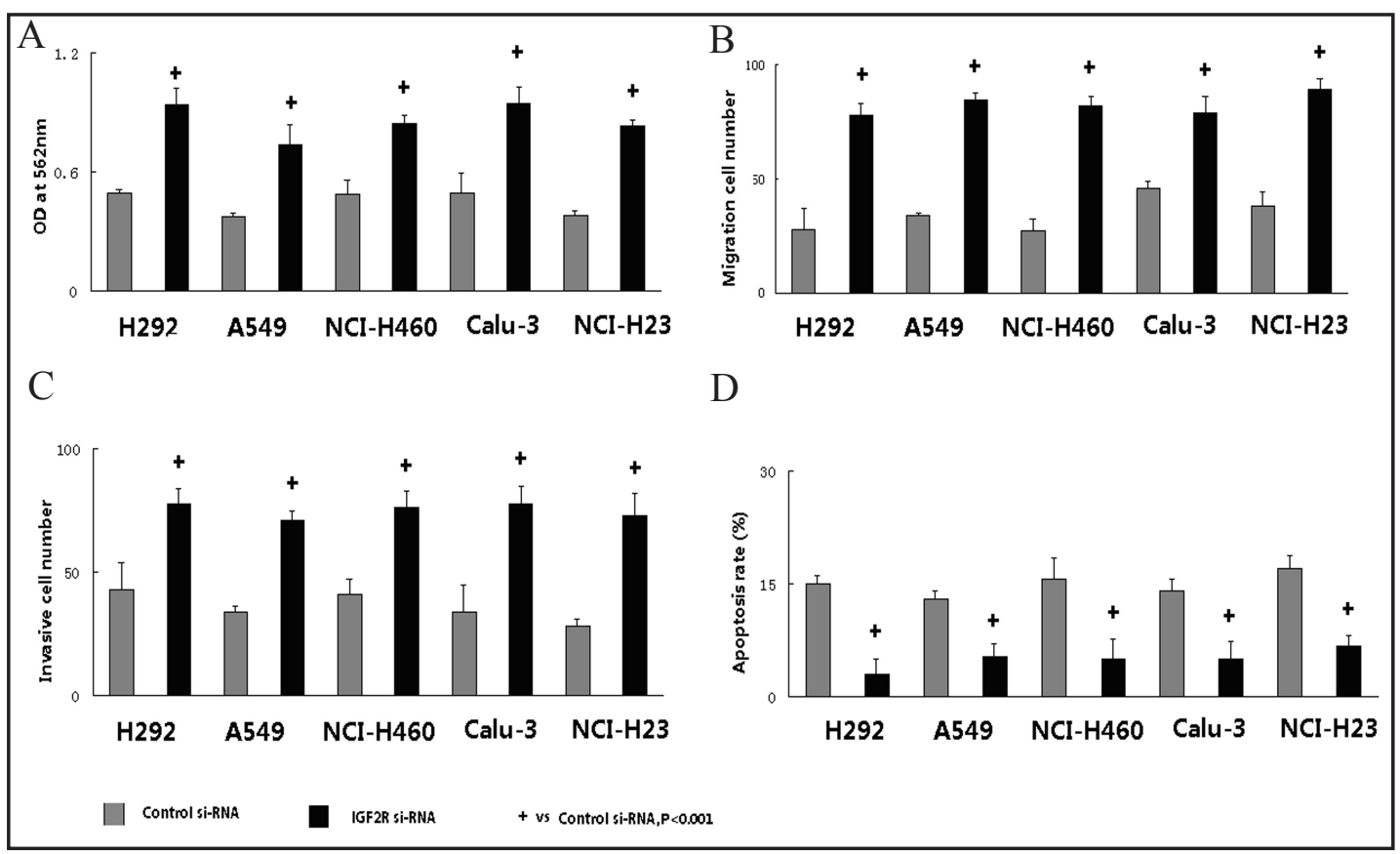

Fig. 4. Proliferation, migration and invasion of NSCLLC cell lines after IGF2R si-RNA transfection. Fig. 4a reveals the cell growth rates detected by MTT Cell Proliferation Assay were significantly increased in NSCLC cell lines after IGF2R si-RNA transfection compared to cells treated with control si-RNA from cell proliferation assays ( all $\mathrm{P}<0.001$ ). Fig. $4 \mathrm{~b}$ shows the results of transwell migration assay. Our data shows that IGF2R inhibition dramatically increased the migration ability in cells transfected with IGF2R si-RNA transfection (all $\mathrm{P}<0.001$, compared to cells treated with control si-RNA). Fig. $4 \mathrm{c}$ indicates the comparison of the invasive abilities among all NSCLC cell lines using transwell migration assay. Our data show that gene silencing of IGF2R dramatically enhanced the invasive ability of all NSCLC cell lines (all $\mathrm{P}<0.001$, compared to cells treated with control si-RNA). Fig. 4d shows the apoptosis rates in NSCLC cell lines by TUNEL assay. Apoptosis rate was indexed by counting TUNEL positive cells per 100 nuclei per section*100\%. Our data shows that apoptosis rates were significantly decreased in cell lines after IGF2R si-RNA silencing (all $\mathrm{P}<0.001$, compared to cells treated with control si-RNA).

\section{Discussion}

The IGFR signaling pathway regulates cell growth and development, which is essential for normal lung development and growth $[19,20]$. As a multifunctional protein receptor, IGF2R can bind IGF2 at the cell surface and regulates the IGFR signaling pathway [21]. The role of IGF2R in NSCLC remains largely unknown. Our results indicate that IGF2R expression was significantly associated with the smoking status, tumor stage and differentiation status. More importantly, we found that IGF2R expression was significantly related to the chemotherapy response and prognosis of NSCLC3 patients. Our in vitro studies showed that the IGF2R affected the cell proliferation rate, migration and invasive ability and apoptosis rate. In addition, IGF2R also regulates the chemosensitivity to cisplatin in NSCLC cell lines.

IGF2 can activate the IGFR signaling, which plays an important role in NSCLC growth and proliferation $[22,23]$.The IGF2R only binds IGF-2 and functions for trafficking excess ligand to lysosomes for degradation and/or directly mediating IGF2 signaling [18, 24]. IGF2R inhibits the IGFR signaling pathway. Fig. 6 shows the possible molecular mechanism involved in the process: IGF2s bind IGF1R and activate IGF axis signal; subsequently, IGF2R degrades IGF2 on cell surface to attenuate IGF signaling, and then to transport IGF2 to the lysosome; Lastly, IGF2 degrades in lysosome and IGF2R is recycled.

Previous studies show that activity of IGF/IGFR signaling pathway are over-activated in NSCLC patients. The IGFs, IGFRs and subsequent downstream mediators such as Ras/ 


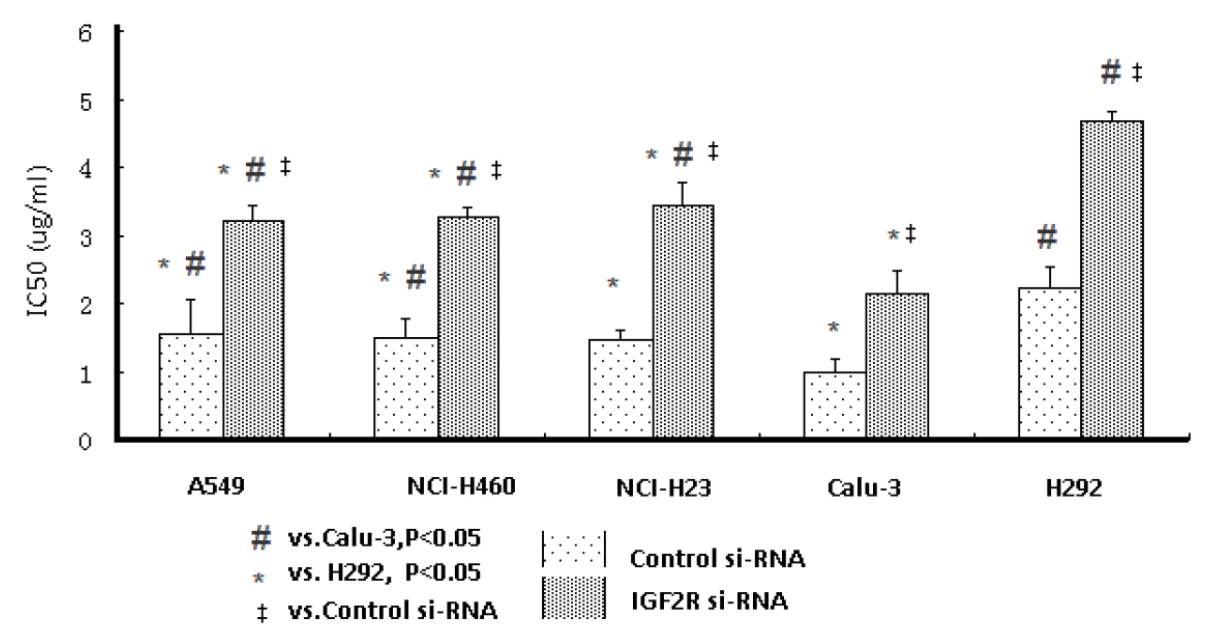

Fig. 5. The IGF2R si-RNA transfection induced chemosensitivity to cisplatin in cultured cancer cells. The IC50 concentration of cisplatin for IGF2R si-RNA transfected cells increased significantly than control cells (A549: 3.32 vs. $1.59 \mathrm{ug} / \mathrm{ml}$; NCI-H460: 3.402 vs. $1.52 \mathrm{ug} / \mathrm{ml}$; NCI-H23: 3.56 vs. 1.62 ug/ml; Calu-3: 2.06 vs. $1.03 \mathrm{ug} / \mathrm{ml} ; \mathrm{H} 292$ : 4.71 vs. $2.26 \mathrm{ug} / \mathrm{ml}$; all $\mathrm{P}<0.01$ ), indicating that IGF2R silencing significantly enhanced the chemo-resistance of NSCLC cell lines to cisplatin treatment. When the IC50 were compared among different cell lines, we found that the cell lines with lower IGF2R (H292) expression tend to have higher IC50 than those with higher IGF2R expression. Pearson analyses revealed a negative corelateion between the IC50 and the IGF2R expression ( $\mathrm{r}=-0.87, \mathrm{P}=0.002$ ).

Fig. 6. The role of IGF2R in IGF axis (illustration for discussion).

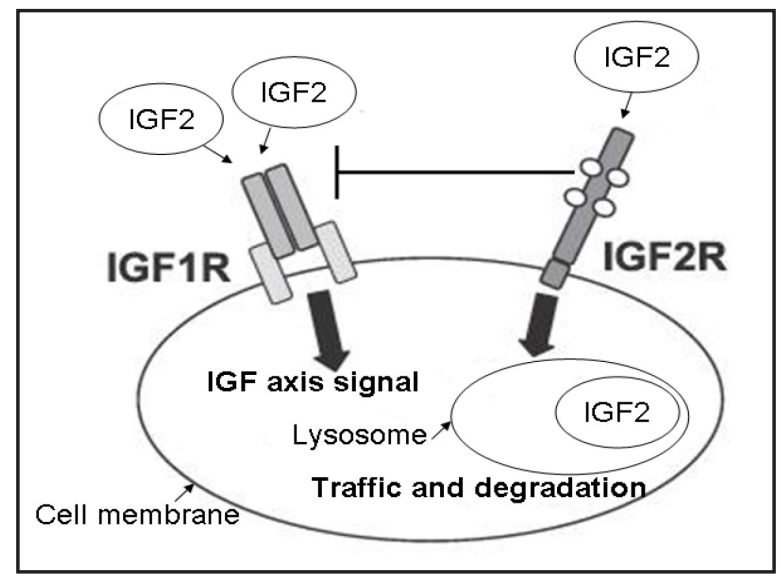

Raf or the PI3K/Akt regulate some fundamental cellular processes including proliferation and migration $[25,26]$. A higher serum IGF2 is associated with increased risk for cancer development [27]. IGF2R is implicated to the regulation of tumor cell growth and is associated with advanced stages in NSCLC patients [28, 29]. In this study we found that the overall frequency of down-regulation of IGF2R gene expression is higher in smokers than non-smokers. IGF2R protein expression is also associated with smoking in NSCLC patients and the IGFR signaling pathway is activated with the down-regulation of IGF2R expression when exposed to smoking.

We used the human lung cancer cell lines H292, A549, NCI-H460, Calu-3, NCI-H23 to study the effects of IGF2R on cell biological behaviors. IGFR signaling pathway plays an important role in regulating cell proliferation, differentiation, apoptosis, and transformation 
in these cells. There is a strong link of rapidly altered metabolic activity induced by target inhibition of the IGF-1R signaling pathways in proliferating cells. Through direct interaction with IGF1R $\beta$, SM22 $\alpha$ overexpression enhances tumor cell growth and activates the IGF1R/ PI3K/Akt pathway $[30,31]$. Our results show that IGF2R also regulates cell proliferation, apoptosis, migration, and invasive ability. IGF2R does not have tyrosine kinase activity and acts like an antagonist to IGF-2, thus, IGF2R may possibly regulates the NSCLC cell fates in our experiment by accelerating the degradation of IGF- 2 .

Several limitations need to be addressed. Firstly, the sample size of this study is relatively small. A larger sample size will reduced the bias possibility in illustrating the association of IGF2R and NSCLC. Secondly, the interaction between IGF2R with IGF1, IGF1R and IGF2 are not studied. Thirdly, the molecular mechanism under which IGF2R affect the chemotherapy response still needs to be elucidated.

\section{Acknowledgements}

This research was supported by the Foundation of The health department of Heilongjiang Province (Grand No. 2013080).

\section{References}

1 Kocaturk CI, Gunluoglu MZ, Cansever L, Dincer IS, Bedirhan MA: Prognosis in patients with non-small cell lung cancer and satellite tumors. Thorac Cardiovasc Surg 2011;59:360-363.

-2 Costa GJ, Fernandes AL, Pereira JR, Curtis JR, Santoro IL: Survival rates and tolerability of platinumbased chemotherapy regimens for elderly patients with non-small-cell lung cancer (nsclc). Lung Cancer 2006;53:171-176.

3 Chang CH, Chen KY, Young-Xu Y, Kurth T, Orav EJ, Yang PC, Chan KA: The safety and efficacy of gefitinib versus platinum-based doublets chemotherapy as the first-line treatment for advanced non-small-cell lung cancer patients in east asia: A meta-analysis. Lung Cancer 2008;62:242-252.

4 Hotta K, Kiura K: Role of platinum-based radio-chemotherapy for locally advanced non-small-cell lung cancer: Possible influence of type of platinum on survival data. Ann Oncol 2006;17:1724.

5 d'Amato TA, Landreneau RJ, Ricketts W, Huang W, Parker R, Mechetner E, Yu IR, Luketich JD: Chemotherapy resistance and oncogene expression in non-small cell lung cancer. J Thorac Cardiovasc Surg 2007;133:352363.

6 Han M, Liu Q, Yu J, Zheng S: Identification of candidate molecular markers predicting chemotherapy resistance in non-small cell lung cancer. Clin Chem Lab Med 2010;48:863-867.

7 Dziadziuszko R, Camidge DR, Hirsch FR: The insulin-like growth factor pathway in lung cancer. J Thorac Oncol 2008;3:815-818.

-8 Velcheti V, Govindan R: Insulin-like growth factor and lung cancer. J Thorac Oncol 2006;1:607-610.

-9 Schairer C, McCarty CA, Isaacs C, Sue LY, Pollak MN, Berg CD, Ziegler RG: Circulating insulin-like growth factor (igf)-i and igf binding protein (igfbp)-3 levels and postmenopausal breast cancer risk in the prostate, lung, colorectal, and ovarian cancer screening trial (plco) cohort. Horm Cancer 2010;1:100-111.

10 Weroha SJ, Haluska P: The insulin-like growth factor system in cancer. Endocrinol Metab Clin North Am 2012;41:335-350, vi.

11 Pollak M: The insulin receptor/insulin-like growth factor receptor family as a therapeutic target in oncology. Clin Cancer Res 2012;18:40-50.

12 Oates AJ, Schumaker LM, Jenkins SB, Pearce AA, DaCosta SA, Arun B, Ellis MJ: The mannose 6-phosphate/ insulin-like growth factor 2 receptor (m6p/igf2r), a putative breast tumor suppressor gene. Breast Cancer Res Treat 1998;47:269-281.

13 Kong FM, Anscher MS, Washington MK, Killian JK, Jirtle RL: M6p/igf2r is mutated in squamous cell carcinoma of the lung. Oncogene 2000;19:1572-1578.

14 Mountzios G, Kostopoulos I, Kotoula V, Sfakianaki I, Fountzilas E, Markou K, Karasmanis I, Leva S, Angouridakis N, Vlachtsis K, Nikolaou A, Konstantinidis I, Fountzilas G: Insulin-like growth factor 1 receptor (igf1r) expression and survival in operable squamous-cell laryngeal cancer. PLoS One 2013;8:e54048. 
15 Peled N, Wynes MW, Ikeda N, Ohira T, Yoshida K, Qian J, Ilouze M, Brenner R, Kato Y, Mascaux C, Hirsch FR: Insulin-like growth factor-1 receptor (igf-1r) as a biomarker for resistance to the tyrosine kinase inhibitor gefitinib in non-small cell lung cancer. Cell Oncol (Dordr) 2013;36:277-288.

16 Wang X, Cui E, Zeng H, Hua F, Wang B, Mao W, Feng X: Rage genetic polymorphisms are associated with risk, chemotherapy response and prognosis in patients with advanced nsclc. PLoS One 2012;7:e43734.

17 El-Shewy HM, Lee MH, Obeid LM, Jaffa AA, Luttrell LM: The insulin-like growth factor type 1 and insulinlike growth factor type 2/mannose-6-phosphate receptors independently regulate erk1/2 activity in hek293 cells. J Biol Chem 2007;282:26150-26157.

18 Harris LK, Crocker IP, Baker PN, Aplin JD, Westwood M: Igf2 actions on trophoblast in human placenta are regulated by the insulin-like growth factor 2 receptor, which can function as both a signaling and clearance receptor. Biol Reprod 2011;84:440-446.

19 Yu H, Rohan T: Role of the insulin-like growth factor family in cancer development and progression. Journal of the National Cancer Institute 2000;92:1472-1489.

20 Wang Z, Wang Z, Liang Z, Liu J, Shi W, Bai P, Lin X, Magaye R, Zhao J: Expression and clinical significance of igf-1, igfbp-3, and igfbp-7 in serum and lung cancer tissues from patients with non-small cell lung cancer. OncoTargets and therapy 2013;6:1437-1444.

21 Souza RF, Wang S, Thakar M, Smolinski KN, Yin J, Zou TT, Kong D, Abraham JM, Toretsky JA, Meltzer SJ: Expression of the wild-type insulin-like growth factor ii receptor gene suppresses growth and causes death in colorectal carcinoma cells. Oncogene 1999;18:4063-4068.

-22 Zhang ZF, Pei BX, Wang AL, Zhang LM, Sun BS, Jiang RC, Wang CL: Expressions of cldn1 and insulin-like growth factor 2 are associated with poor prognosis in stage $\mathrm{n} 2 \mathrm{non}$-small cell lung cancer. Chinese medical journal 2013;126:3668-3674.

23 Hou X, Hu Z, Huang X, Chen Y, He X, Xu H, Wang N: Serum osteopontin, but not opn gene polymorphism, is associated with lvh in essential hypertensive patients. J Mol Med (Berl) 2014;92:487-495.

24 Hou XW, Son J, Wang Y, Ru YX, Lian Q Majiti W, Amazouzi A, Zhou YL, Wang PX, Han ZC: Granulocyte colonystimulating factor reduces cardiomyocyte apoptosis and improves cardiac function in adriamycin-induced cardiomyopathy in rats. Cardiovasc Drugs Ther 2006;20:85-91.

-25 Peng Y, Dai Y, Hitchcock C, Yang X, Kassis ES, Liu L, Luo Z, Sun HL, Cui R, Wei H, Kim T, Lee TJ, Jeon YJ, Nuovo GJ, Volinia S, He Q, Yu J, Nana-Sinkam P, Croce CM: Insulin growth factor signaling is regulated by microrna-486, an underexpressed microrna in lung cancer. Proceedings of the National Academy of Sciences of the United States of America 2013;110:15043-15048.

-26 Yi L, Hou X, Zhou J, Xu L, Ouyang Q, Liang H, Zheng Z, Chen H, Xu M: Hif-1alpha genetic variants and protein expression confer the susceptibility and prognosis of gliomas. Neuromolecular Med 2014;16:578-586.

27 Ghosh P, Dahms NM, Kornfeld S: Mannose 6-phosphate receptors: New twists in the tale. Nature reviews Molecular cell biology 2003;4:202-212.

-28 Kotsinas A, Evangelou K, Sideridou M, Kotzamanis G, Constantinides C, Zavras AI, Douglass CW, Papavassiliou AG, Gorgoulis VG: The 3' utr igf2r-a2/b2 variant is associated with increased tumor growth and advanced stages in non-small cell lung cancer. Cancer letters 2008;259:177-185.

29 Jing M, Li B, Hou X, Shoba J, Li C, Liang H, Zhang X, Liu E, Yang B, Meng X: Opn gene polymorphism and the serum opn levels confer the susceptibility and prognosis of ischemic stroke in chinese patients. Cell Physiol Biochem 2013;32:1798-1807.

-30 Kim TR, Cho EW, Paik SG, Kim IG: Hypoxia-induced sm22alpha in a549 cells activates the igf1r/pi3k/akt pathway, conferring cellular resistance against chemo- and radiation therapy. FEBS letters 2012;586:303309.

31 Hou X, Hu Z, Xu H, Xu J, Zhang S, Zhong Y, He X, Wang N: Advanced glycation endproducts trigger autophagy in cadiomyocyte via rage/pi3k/akt/mtor pathway. Cardiovasc Diabetol 2014;13:78. 